\title{
Density Functional Theory Analysis of Poly Glycolic Acid with Metal Ions $\left(\mathrm{Na}^{+}, \mathrm{K}^{+}\right)$ Interaction
}

\author{
Mahendiraprabu Ganesan, Selvarengan Paranthaman
}

\begin{abstract}
The complexation between Poly glycolic acid (PGA) and alkali metal ions $\left(\mathrm{Na}^{+}, \mathrm{K}^{+}\right)$have been studied using B3LYP/6-311++G** method. The binding site of metal ion interaction on PGA is carbonyl oxygen. Both metal ions form bidendate complexation with PGA. Further, it can be noted that the PGA with $\mathrm{K}^{+}$complex is more stable than the PGA with $\mathrm{Na}^{+}$ complex. The binding affinities $(\Delta H)$, basicity $(\Delta G)$ and the complexation entropies (US) of all the studied systems are calculated. The interaction energy is maximum in PGA-Nat than the PGA-K $\mathrm{K}^{+}$complex. This is due to more charge transfer taking place between PGA and Na. The stability of the complex is studied by the chemical hardness value. The condensed Fukui functions are calculated and are used to predict the favourable reactive site.
\end{abstract}

Keywords: Polyglycolic acid, chemical hardness, condensed Fukui functions, density functional theory calculations, metal ions.

\section{INTRODUCTION}

I In the past few years, biologically important natural and synthetic polymers, such as collagen [1], chitin [2], chitosan [3] proteins [4], polyhydroxybutyrate(PHB) [5], polylactic acid (PLA) [6], polyglycolic acid (PGA) [7] and polypropylene (PP) [8] have been used extensively in biological as well as medicinal applications. Among these polymers, polyglycolic acid (PGA) is got attention in the last several decades [9] because of its importance in medicinal industry. In general, the biodegradation of these polymers are due to excessive heat [10], photolysis, hydrolysis, and oxidation. However it is not a big problem when PGA is exposed to physiological conditions. In PGA there are two functional group (-OH and $-\mathrm{COOH})$ were present in the same polymer, therefore the PGA act as a versatile ligand in coordination chemistry [11].

An interaction of metal cation with neutral molecule is an important intermediate step or process in gas-phase chemistry $[12,13]$. Because of this, many efforts have been taken to the investigation of the formation, and reactivity of organometallic complexes of biochemical importance [14-17]. $\alpha$-Hydroxycarboxylic acid is simplest ligand which is presented in many biochemical reactions. Previously, Lic'inia

Revised Manuscript Received on December 15, 2019.

* Correspondence Author

Mahendiraprabu Ganesan, Department of Physics and International Research Centre, Kalasalingam Academy of Research and Education, Krishnankoil-626 126, India. Email: prabuphy24@gmail.com

Selvarengan Paranthaman*, Department of Physics and International Research Centre, Kalasalingam Academy of Research and Education, Krishnankoil-626 126, India. Email: psrengan@hotmail.com et al have performed DFT study of oxoperoxo vanadium(V) complexes. They have studied two glycolic acid metal ion complexes. They have reported the structural modifications far from the metal nucleus and which does not significantly affect the metal chemical shift [18]. Recently, Ersen Göktürk found new approach to synthesize polyglycolic acid (PGA). They have obtained PGA using cationic alternating copolymerization of formaldehyde (from trioxane) and carbon monoxide (CO)[19]. Apart from these studies, there are soA many experimental [20-22] and theoretical [23-28] studies have been carried on the interaction of glycolic acid and its derivatives with metal ions. To the best of our knowledge, no systematic DFT study performed on PGA metal complexes. The present study aims at investigating structure, intermolecular interaction, thermochemical properties and vibrations of PGA when interacting with metal ion $\left(\mathrm{Na}^{+}, \mathrm{K}^{+}\right)$using DFT. The stability of the PGA metal ion interactions also calculated. Condensed Fukui functions are calculated to find the favorable reactive sites of a neutral PGA. The vibrational frequency analysis is also carried out to find out the stretching vibrations of the PGA metal ion complexes.

\section{COMPUTATIONAL DETAILS}

In this study, the DFT calculations are performed to determine the molecular structure, energetics, vibrational frequency and thermochemical properties. Becke's three-parameter hybrid functional [29] combined with the gradient-corrected correlation functional of Lee, Yang, and Parr (LYP) [30] with $6-311++\mathrm{G}^{* *}$ basis set is used for geometry optimization. The basis set superposition error (BSSE) corrected interaction energy between metal cation and PGA is calculated. [31]. The standard thermodynamical calculations [32] are used to obtain the affinities $\left(\Delta \mathrm{H}_{298}\right)$ and basicity $\left(\Delta \mathrm{G}_{298}\right)$ at $298.15 \mathrm{~K}$ and complexation entropies $(\Delta \mathrm{S})$. The DFT reactivity parameter, chemical hardness $(\eta)$ [33] is calculated using the B3LYP/6-311++G** level of theory, using the relation:

$$
\eta=\frac{I-A}{2}
$$

Where I is the ionization potential, and A is electron affinity of the studied system. I and A can be calculated using Koopman's theorem. Condensed Fukui functions are calculated using the mulliken charges which can be obtained from Mulliken population analysis: 
where $\mathrm{f}_{\mathrm{K}}^{+}, \mathrm{f}_{\mathrm{K}}^{-}$and $\mathrm{f}_{\mathrm{K}}^{0}$ are the nucleophilic, electrophilic, and radical attacks, respectively. All the above mentioned calculations are done using Gaussian 09W program. [34]

\section{RESULTS AND DISCUSSION}

PGA, PGA with metal ions complexes are optimized using B3LYP/6-311++G**. The optimized structures of PGA, PGA-Na+ and PGA-K+ in gas phase are shown in Fig. 1. The total energies, van der Waals bond length, interaction energies, dipole moments, chemical hardness, affinities, basicity and complexation entropies for the above complexes are calculated using B3LYP / 6-311++G** and are shown in Table 1. The molecular orbital diagram for the PGA metal ion complexes are shown in Fig. 2. The condensed fukui functions for the PGA structure are shown in Table 2. The vibrational frequency of PGA metal ion complexes are calculated and plotted in Fig. 3.

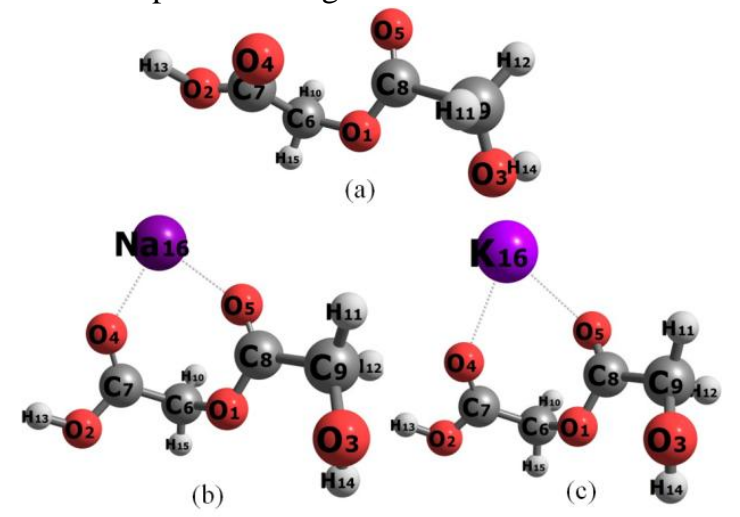

Fig. 1. Optimized structures of (a) PGA, (b) PGA-Na and (c) PGA-K using B3LYP/6-311++G** level of theory.

Table- I: Total Energy (E, in hartree), van der Waals bond length ( $R v$, in $\AA$ ), interaction energy (Eint, in kcal / mol), dipole moment ( $\mu \mathrm{M}$, in Debye), chemical hardness $(\eta$, in eV), affinity ( $\Delta \mathrm{H} 298$, kcal mol-1), basicity ( $\Delta$ G298, kcal mol-1) and complexation entropies $(\Delta S$, cal mol-1 K-1) calculated using B3LYP / 6-311++G** for PGA metal complexes.

\begin{tabular}{lcccc}
\hline & & PGA & PGA-Na $^{+}$ & PGA-K $^{+}$ \\
\hline $\mathrm{E}$ & & -531.98136 & -694.48807 & -1132.14273 \\
$\mathrm{R}_{\mathrm{v}}$ & $\mathrm{C} 7=\mathrm{O} 4$ & & 2.223 & 2.610 \\
& $\mathrm{C} 8=\mathrm{O} 5$ & & 2.257 & 2.642 \\
$\mathrm{E}_{\text {int }}$ & & & 269.83 & 31.38 \\
$\mu_{\mathrm{M}}$ & & 4.24 & 6.70 & 6.85 \\
$\eta$ & & 0.74 & 3.00 & 3.14 \\
$\Delta \mathrm{H}_{298}$ & & & -261.213425 & -249.566846 \\
$\Delta \mathrm{G}_{298}$ & & & -252.804796 & -241.729251 \\
$\Delta \mathrm{S}$ & & & -28.218 & -26.291 \\
\hline
\end{tabular}

From Fig. 1. It can be seen that in the optimized structures of PGA-Na+ and PGA-K+ , the two alkali metals Na+ and K+

$$
\begin{gathered}
\mathrm{f}^{+}{ }_{\mathrm{K}}=\mathrm{q}_{\mathrm{k}}(\mathrm{N}+1)-\mathrm{q}_{\mathrm{K}}(\mathrm{N}) \\
\mathrm{f}_{\mathrm{K}}=\mathrm{q}_{\mathrm{k}}(\mathrm{N})-\mathrm{q}_{\mathrm{K}}(\mathrm{N}-1) \\
\mathrm{f}_{\mathrm{K}}^{0}=1 / 2\left[\mathrm{q}_{\mathrm{k}}(\mathrm{N}+1)-\mathrm{q}_{\mathrm{K}}(\mathrm{N}-1)\right]
\end{gathered}
$$

form bidentate complexation with PGA. That is with the carbonyl oxygen group of PGA. Further, from the energy values it can be understand that the PGA-K+ complex is energetically more stable than the PGA-Na+ (Table 1). But in the case of van der Waals bond length, the bond length of the PGA-Na+ complex is forming very strong interaction with PGA compared with PGA-K+ complex. This is due to the low molecular weight of Sodium ion. Earlier Selvarengan et al have discussed the relative energy of the glycine conformers with alkali metal ion complexes. [35]. The dipole moment value for PGA, PGA-Na+ and PGA-K+ are 4.24, 6.70 and 6.85 $\mathrm{D}$ respectively. The dipole moment value increases as the size of the metal ion increases. In this same way the chemical hardness values also increased while metal ions interact with the pure PGA. The chemical hardness value of PGA, PGA-Na+ and PGA-K+ are 0.74, 3.00 and $3.14 \mathrm{eV}$. From the above hardness value $\mathrm{PGA}-\mathrm{K}+$ is more stable than the PGA-Na+ interaction. In summary, $\mathrm{K}+$ interaction with PGA increases the stability of the system. This can be confirmed from chemical hardness values also.

Thermochemical properties such as $\Delta \mathrm{H} 298, \Delta \mathrm{G} 298$, and $\Delta \mathrm{S}$ are calculated using B3LYP / 6-311++G**. The $\Delta \mathrm{H} 298$ for PGA-Na+ and PGA-K+ are -261.213425 and -249.566846 kcal mol-1 respectively. The $\Delta \mathrm{G} 298$ for PGA-Na+ and PGA-K+ are -252.804796 and $-241.729251 \mathrm{kcal}$ mol-1. This indicates that as the size of the metal ions increases, the thermochemical values decreases. Further, this coincides very well with the interaction energy values. The interaction energy is maximum in sodium binding with PGA than potassium binding.[35].This is due to more charge transfer taking place between PGA and Na than PGA and K.

Table- II: Calculated Fukui functions for PGA at B3LYP level of theory using $6-311++G * *$ basis set.

\begin{tabular}{cccc}
\hline PGA & $\mathbf{f}^{+}$ & $\mathbf{f}^{\mathbf{0}}$ & $\mathbf{f}^{-}$ \\
\hline O1 & 0.033 & 0.045 & 0.057 \\
O2 & 0.026 & 0.022 & 0.018 \\
O3 & 0.198 & 0.086 & -0.026 \\
O4 & $\mathbf{0 . 0 3 9}$ & $\mathbf{0 . 0 1 8}$ & $\mathbf{- 0 . 0 0 3}$ \\
O5 & $\mathbf{0 . 2 8 4}$ & $\mathbf{0 . 1 5 8}$ & $\mathbf{0 . 0 3 3}$ \\
C6 & -0.028 & -0.844 & -1.660 \\
C7 & 0.015 & 0.091 & 0.166 \\
C8 & 0.065 & 0.195 & 0.324 \\
C9 & 0.002 & -0.514 & -1.030 \\
H10 & 0.038 & 0.221 & 0.404 \\
H11 & 0.100 & 0.079 & 0.058 \\
H12 & 0.081 & 0.206 & 0.331 \\
H13 & 0.028 & 0.604 & 1.180 \\
H14 & 0.062 & 0.332 & 0.603 \\
H15 & 0.056 & 0.301 & 0.546 \\
\hline
\end{tabular}

The condensed Fukui functions of PGA and PGA metal ion complexes are calculated and are given in Table 2. Fukui functions are used to predict the favourable reactive site for the particular molecule or ligand. From the above table the reactive binding site for PGA is the carbonyl oxygen namely $=\mathrm{O} 4$ and $=\mathrm{O} 5$ respectively. 
The result shows that all the carbonyl oxygen sites are positively charged and it would be a electrophilic attack. So that it is easily to understand, the carbonyl oxygen group are ready to accept the pair of electron to form a covalent bonding. Earlier, senthilkumar et al studied the Fukui function for the Halomethane molecule. They have successfully predicted the better results by using Fukui function [36]. Also selvarengan et al studied the condensed Fukui functions for the glycine molecule. They have also successfully predicted the reactive binding site for the particular glycine conformer.

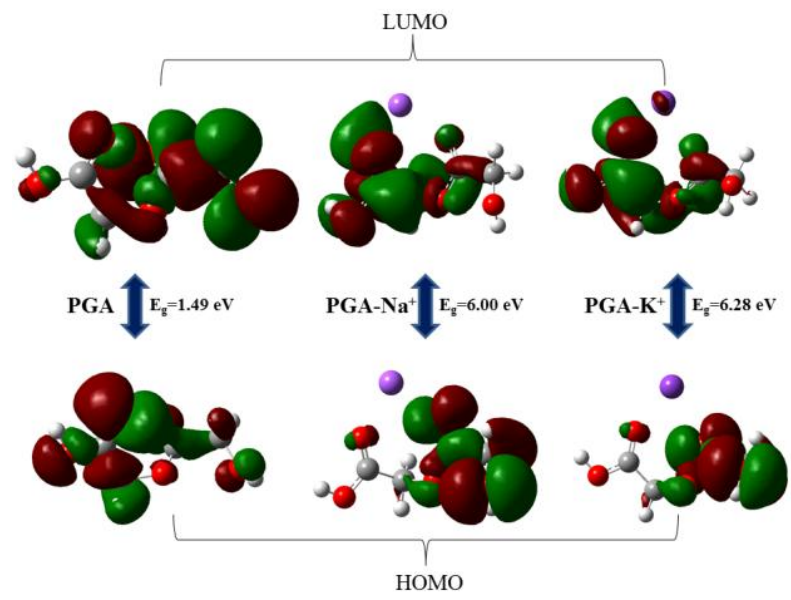

Fig. 2. HOMO to LUMO energy level diagrams of PGA with metal ion complexes.

The frontier molecular orbitals (HOMO and LUMO) were explained by the electronic absorption properties [37]. The energy gap between HOMO and LUMO is a critical parameter property for quantum chemistry [38]. The calculated HOMO to LUMO energy level diagrams for PGA metal ion interactions are shown in Fig. 2. The energy gap between HOMO to LUMO for PGA, PGA-Na+ and PGA-K+ are $1.49,6.00$ and $6.28 \mathrm{eV}$ respectively. This indicates that PGA-K+ complexes are more stable than PGA-Na+ complex. This is consistent with the chemical hardness values.

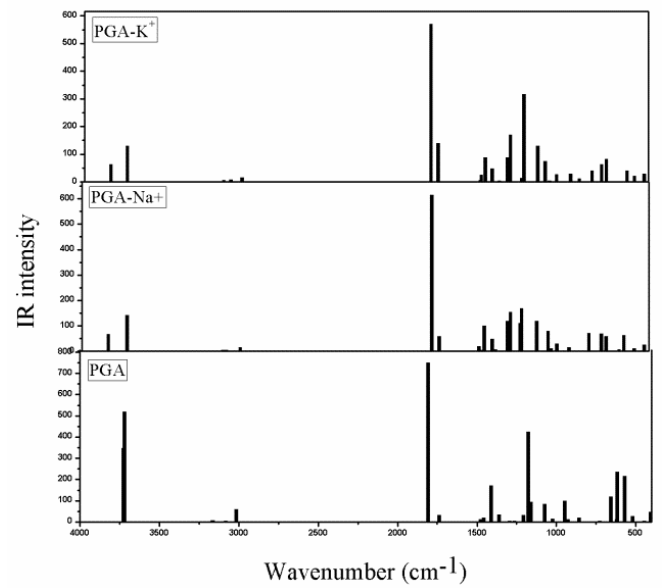

Fig. 3. Calculated vibrational frequency of PGA, PGA-Na+ and PGA-K+ using B3LYP/6-311++G** level of theory

The vibrational frequency of the PGA and PGA metal ion complexes are calculated using B3LYP/6-311++G** level of theory and plotted in Fig. 3. From the above figure we can clearly understand that, there is some peaks are disappears with the PGA. This is due to the presence of metal ion and some peaks are appears while metal ions were interact

interaction. Earlier, Kister et al have studied the morphology of PGA using IR and Raman spectroscopy by experimental study. They also reported the FTIR and FT-Raman spectrum for the PGA crystal. For our cases the vibration stretching mode of carbonyl oxygen $v(\mathrm{C}=\mathrm{O})$ group is very important to study the alkali metal ion interaction, because of the alkali metal particularly interact with these carbonyl oxygen only. Theoretically, vibration frequency of $v(\mathrm{C}=\mathrm{O})$ stretching for PGA, PGA-Na+ and PGA-K+ are 1809, 1778 and $1788 \mathrm{~cm}-1$ respectively. Experimentally Kister et al result for $v(\mathrm{C}=\mathrm{O})$ stretching is $1760 \mathrm{~cm}-1$ with very strong vibration. Our theoretical results are exactly matching with the available experimental data [20].

\section{CONCLUSION}

The DFT method is used to study the Polyglycolic acid complexation with alkali metal ions. From the calculated van der Waals bond length, it can be understand that PGA and $\mathrm{Na}^{+}$ complex is stronger than the PGA- $\mathrm{K}^{+}$complex. From the calculated dipole moment, chemical hardness, affinities, basicity and complexation entropies of PGA metal complexes, PGA with potassium ion $\left(\mathrm{PGA}-\mathrm{K}^{+}\right)$is the most stable than the PGA-Na ${ }^{+}$complex. The interaction energy is maximum in PGA-Na ${ }^{+}$than the PGA- $\mathrm{K}^{+}$complex. This is due to more charge transfer taking place between PGA and Na. From the condensed Fukui functions, it can be concluded that the carbonyl oxygen is reactive binding site of PGA. These sites are more favorable for electrophilic attack. The carbonyl oxygen stretching frequency coincides well with the experimental data.

\section{ACKNOWLEDGMENT}

M. G. sincerely thanks Kalasalingam Academy of Research and Education for the award of University Research Fellowship (URF). S. P. is thankful to the management of Kalasalingam Academy of Research and Education for providing the financial support to establish the computational research facility at the International Research Centre (IRC), Kalasalingam Academy of Research and Education..

\section{REFERENCES}

1. A. A. Haroun, "Preparation and characterization of biodegradable thermoplastic films based on collagen hydrolyzate," J. Appl. Polym. Sci., 2010, vol. 115, pp. 3230-3237.

2. S. Nsereko and M. Amiji, "Localized delivery of paclitaxel in solid tumors from biodegradable chitin microparticle formulations," Biomaterials., 2002, vol. 23, pp. 2723-2731.

3. T. Bourtoom and M. S. Chinnan, "Preparation and properties of rice starch-chitosan blend biodegradable film," LWT., 2008 vol. 41, pp. 1633-1641.

4. V. R. Sinha and A. Trehan, "Biodegradable microspheres for protein delivery," J. Control. Release, 2003, vol. 90, pp. 261-280.

5. M. Unverdorben, A. Spielberger, M. Schywalsky, D. Labahn, S Hartwig, M. Schneider, D. Lootz, D. Behrend, K. Schmitz, R. Degenhardt and M. Schaldach, "A polyhydroxybutyrate biodegradable stent: preliminary experience in the rabbit," CardioVasc. Interv. Radiol., 2002, vol. 25, pp. 127-132.

6. D. E. Cutright and E. E. Hunsuck, "The repair of fractures of the orbital floor using biodegradable polylactic acid," Oral Surg. Oral Med. Oral Pathol., 1972, vol. 33, pp. 28-34. 


\section{Density Functional Theory Analysis of Poly Glycolic Acid with Metal Ions $\left(\mathrm{Na}^{+}, \mathrm{K}^{+}\right)$Interaction}

7. M. L. Cooper, J. F. Hansbrough, R. L. Spielvogel, R. Cohen, R. L. Bartel and G. Naughton, "In vivo optimization of a living dermal substitute employing cultured human fibroblasts on a biodegradable polyglycolic acid or polyglactin mesh," Biomaterials., 1991, vol. 12, pp. 243-248.

8. A. Keller, "Compounding and mechanical properties of biodegradable hemp fibre composites," Comp. Sci. Tech., 2003, vol. 63, pp. 1307-1316.

9. H. M. De Oca, D. F. Farrar and I. M. Ward, "Degradation studies on highly oriented poly (glycolic acid) fibres with different lamellar structures," Acta. Biomater., 2011, vol. 7, pp. 1535-1541.

10. R. U. S. T. G. I. Chandra, "Biodegradable polymers. Progress in polymer science," 1998, vol. 23, pp. 1273-1335

11. F. J. Caires, L. S. Lima, D. J. C. Gomes, A. C. Gigante, O. Treu-Filho and M. Ionashiro, "Thermal and spectroscopic studies of solid oxamate of light trivalent lanthanides," J. Therm. Anal. Calorim., 2013, vol. 111, pp. 349-355.

12. K. Eller and H. Schwarz, "Organometallic chemistry in the gas phase," Chem. Rev., 1991, vol. 91, pp. 1121-1177.

13. Fontijn, A. ed., 2017. Gas phase metal reactions. Elsevier.

14. S. E. Taylor, "Metal ions in genetic information transfer: GL Eichhorn and LG Marzilli, eds," Elsevier North-Holland, New York, 1981, pp. 340

15. A. Sigel and H. Sigel Eds, "Metal ions in biological systems," Marcel Dekker: New York, 1996; vol. 32 and 33.

16. D. K. Karlin and J. Zubieta Eds, "Biological and Inorganic Copper Chemistry," Adenine Guiderland: New York, 1986, vol. I and II.

17. D. M. Whitfield, S. Stojkovski and B. Sarkar, Coord. Chem. Rev. 1993., vol. 122, pp. 171-225.

18. L. L. Justino, M. L. Ramos, M. Kaupp, H. D. Burrows, C. Fiolhais and V. M. Gil, "Density functional theory study of the oxoperoxo vanadium (V) complexes of glycolic acid. Structural correlations with NMR chemical shifts," Dalton.Trans., 2009, vol. 44, pp. 9735-9745.

19. E. Göktürk, A. G. Pemba and S. A. Miller, "Polyglycolic acid from the direct polymerization of renewable C1 feedstocks," Poly. Chem., 2015, vol. 6, pp. 3918-3925.

20. G. Kister, G. Cassanas and M. Vert, "Morphology of poly (glycolic acid) by IR and Raman spectroscopies," Spectrochim. Acta. A., 1997, vol. 53, pp. 1399-1403.

21. L. Boutreau, P. Toulhoat, J. Tortajada, A. Luna, O. Mó and M. Yáñez, "Reactions between glycolic acid and $\mathrm{Cu}+$ in the gas phase. An experimental and theoretical study," J. Phys. Chem. A., 2002, vol. 106, pp. 9359-9368.

22. H. Sato, M. Miyada, S. Yamamoto, K. R. Reddy and Y. Ozaki, "C-H * $\mathrm{O}$ (ether) hydrogen bonding along the (110) direction in polyglycolic acid studied by infrared spectroscopy, wide-angle X-ray diffraction, quantum chemical calculations and natural bond orbital calculations," RSC Adv., 2016, vol. 6, pp. 16817-16823.

23. A. L. C. S. do Nascimento, J. A. Teixeira, W. D. G. Nunes, D. J. C. Gomes, C. Gaglieri, O. Treu-Filho, M. Pivatto, F. J. Caires and M. Ionashiro, "Thermal behavior of glycolic acid, sodium glycolate and its compounds with some bivalent transition metal ions in the solid state," J. Therm. Anal. Calorim., 2017, vol. 130, pp. 1463-1472.

24. A. C. Tsipis, C. A. Tsipis and V. Valla, "Quantum chemical study of the coordination of glycolic acid conformers and their conjugate bases to [Ca (OH2) n] 2+(n= 0-4) ions,"J. Mol. Struct. THEOCHEM., 2003, vol. 630, pp. 81-100.

25. T. Casalini, F. Rossi, M. Santoro and G. Perale, "Structural Characterization of Poly-l-lactic Acid (PLLA) and Poly (glycolic acid)(PGA) Oligomers," Int. J. Mol. Sci., 2011, vol. 12, pp. 3857-3870

26. S. P. Ju, W. C. Huang and C. C. Chen, "The hydrolysis mechanism of polyglycolic acid under tensile mechanical loading: a density functional theory study," RSC Adv., 2014, vol. 4, pp. 35862-35867.

27. C. Chen, S. P. Ju, W. C. Huang, J. S. Lin and C. C. Chen, "Prediction of the variation of PGA strength during hydrolysis by a combination of empirical equation, density functional theory calculation, and molecular dynamics simulation," AIP Adv., 2014, vol. 4, pp. 077104 (1-12)

28. S. Matsunaga, "Molecular dynamics study on glycolic acid in the physiological salt solution," In IOP Conference Series: Mat. Sci. Eng., 2018, vol. 369, pp. 012014.

29. A. D. Becke, "Density-functional thermochemistry. III. The role of exact exchange," J. Chem. Phys., 1993, vol. 98, pp. 5648-5652.

30. C. Lee, W. Yang and R. G. Parr, "Development of the Colle-Salvetti correlation-energy formula into a functional of the electron density," Phys. Rev., B. 1988, vol. 37, pp. 785-789.

31. S. F. Boys and F. D. Bernardi, "The calculation of small molecular interactions by the differences of separate total energies: Some procedures with reduced errors," Molecular Physics., 1970, vol. 19, pp 553-566.

32. J. E. Del Bene, H. D. Mettee, M. J. Frisch, B. T. Luke and J. A. Pople, "Ab initio computation of the enthalpies of some gas-phase hydration reactions," J. Phys. Chem., 1983, vol. 87, pp. 3279-3282.

33. W. Yang and W. J. Mortier, "The use of global and local molecular parameters for the analysis of the gas-phase basicity of amines," $J$. Am Chem. Soc., 1986, vol. 108, pp. 5708-5711.

34. M. J. Frisch, G. W. Trucks, H. B. Schlegel, G. E. Scuseria, M. A. Robb, J. R. Cheeseman, G Scalmani, V. Barone, B. Mennucci, G. A Petersson, H. Nakatsuji, M. Caricato, X. Li, H. P. Hratchian, A. F. Izmaylov, J. Bloino, G. Zheng, J. L. Sonnenberg, M. Hada, M. Ehara, K. Toyota, R. Fukuda, J. Hasegawa, M. Ishida, T. Nakajima, Y. Honda, O. Kitao, H. Nakai, T. Vreven, J. A Montgomery, Jr., J. E. Peralta, F. Ogliaro, M Bearpark, J. J. Heyd, E. Brothers, K. N. Kudin, V. N. Staroverov, R. Kobayashi, J. Normand, K Raghavachari, A. Rendell, J. C. Burant, S. S. Iyengar, J. Tomasi, M. Cossi, N. Rega, J. M. Millam, M. Klene, J. E. Knox, J. B. ross, V. Bakken, C. Adamo, J. Jaramillo, R. Gomperts, R E. Stratmann, O. Yazyev, A. J. Austin, R. Cammi, C. Pomelli, J. W. Ochterski, R. L. Martin, K Morokuma, V. G. Zakrzewski, G. A. Voth, P Salvador, J. J. Dannenberg, S. Dapprich, A. D Daniels, O. Farkas, J. B. Foresman, J. V. Ortiz, J Cioslowski and D. J. Fox, Gaussian 09, Revision D.01; Gaussian Wallingford, CT, 2009.

35. P. Selvarengan and P. Kolandaivel, "Study of metal ions $(\mathrm{Na}+, \mathrm{K}+)$ interaction with different conformations of glycine molecule," Int. J. Quant. Chem., 2005, vol. 102, pp. 427-434.

36. K. Senthilkumar and P. Kolandaivel, "Hartree-Fock and density functional theory studies on ionization and fragmentation of halomethane molecules by positron impact," Mol. Phys., 2002, vol. 100 pp. 3817-3822.

37. M. Arivazhagan, S. Prabhakaran and R. Gayathri, "Molecular structure, vibrational spectroscopic, first hyperpolarizability, NBO and HOMO, LUMO studies of P-Iodobenzene sulfonyl chloride," Spectrochim. Acta. A., 2011, vol. 82, pp. 332-339.

38. N. Prabavathi, A. Nilufer and V. Krishnakumar, "Quantum mechanical study of the structure and spectroscopic (FT-IR, FT-Raman, 13C, 1H and UV), NBO and HOMO-LUMO analysis of 2-quinoxaline carboxylic acid," Spectrochim. Acta. A., 2002, vol. 92, pp. 325-335. 